\title{
Controlling microstructure in deposits fabricated using powder blown direct energy deposition technique
}
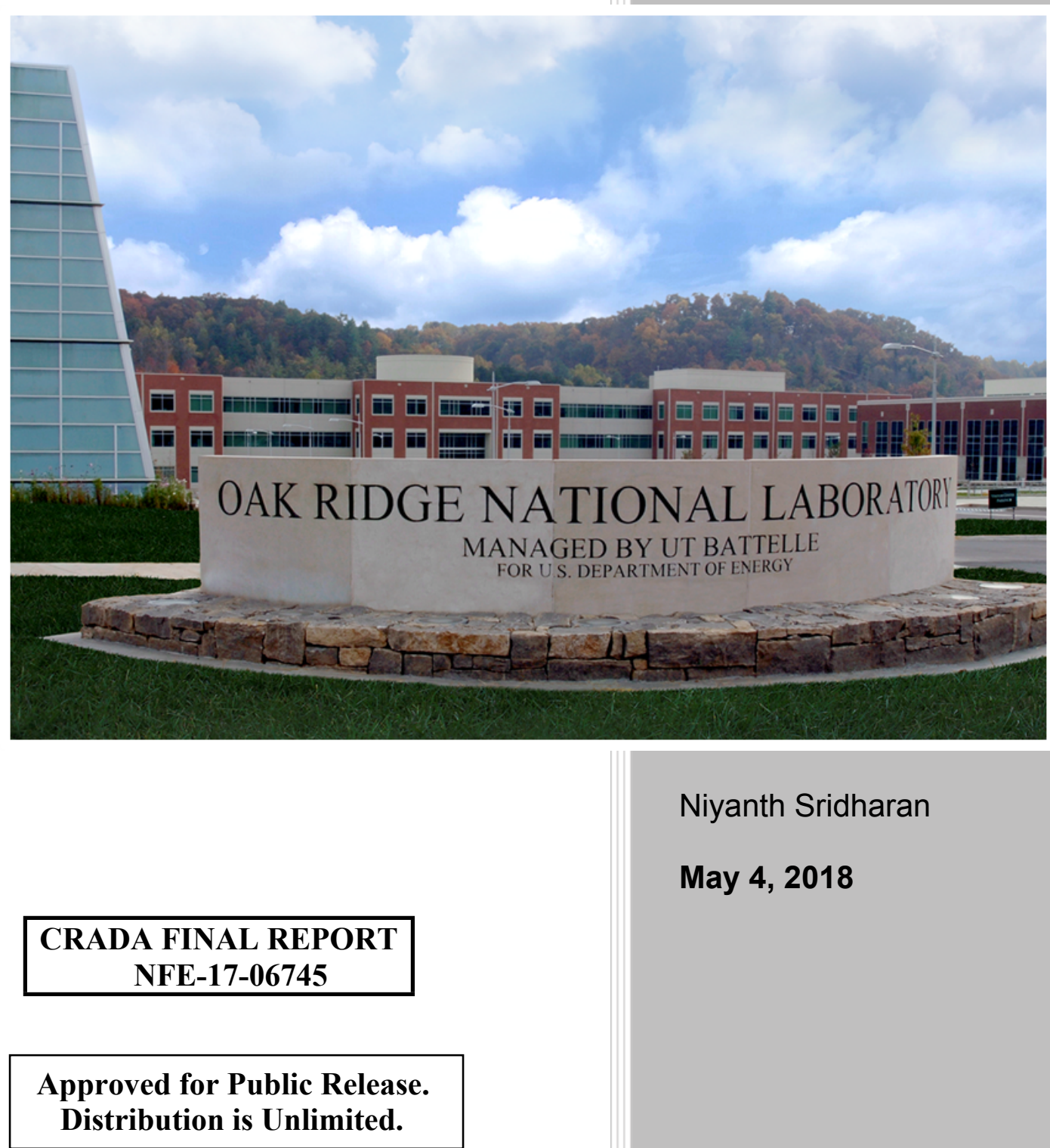

Niyanth Sridharan

May 4, 2018 


\title{
DOCUMENT AVAILABILITY
}

Reports produced after January 1, 1996, are generally available free via US Department of Energy (DOE) SciTech Connect.

Website http://www.osti.gov/scitech/

Reports produced before January 1, 1996, may be purchased by members of the public from the following source:

\author{
National Technical Information Service \\ 5285 Port Royal Road \\ Springfield, VA 22161 \\ Telephone 703-605-6000 (1-800-553-6847) \\ TDD 703-487-4639 \\ Fax 703-605-6900 \\ E-mail info@ntis.gov \\ Website http://www.ntis.gov/help/ordermethods.aspx
}

Reports are available to DOE employees, DOE contractors, Energy Technology Data Exchange representatives, and International Nuclear Information System representatives from the following source:

Office of Scientific and Technical Information

PO Box 62

Oak Ridge, TN 37831

Telephone 865-576-8401

Fax 865-576-5728

E-mail reports@osti.gov

Website http://www.osti.gov/contact.html

This report was prepared as an account of work sponsored by an agency of the United States Government. Neither the United States Government nor any agency thereof, nor any of their employees, makes any warranty, express or implied, or assumes any legal liability or responsibility for the accuracy, completeness, or usefulness of any information, apparatus, product, or process disclosed, or represents that its use would not infringe privately owned rights. Reference herein to any specific commercial product, process, or service by trade name, trademark, manufacturer, or otherwise, does not necessarily constitute or imply its endorsement, recommendation, or favoring by the United States Government or any agency thereof. The views and opinions of authors expressed herein do not necessarily state or reflect those of the United States Government or any agency thereof. 
Materials Science and Technology Division Advanced Manufacturing Office

\title{
CONTROLLING MICROSTRUCTURE IN DEPOSITS FABRICATED USING POWDER BLOWN DIRECT ENERGY DEPOSITION TECHNIQUE
}

\author{
Authors \\ Niyanth Sridharan \\ Narendran Raghavan \\ Brian Jordan \\ Ryan Dehoff \\ Date Published: \\ May 4, 2018 \\ Prepared by \\ OAK RIDGE NATIONAL LABORATORY \\ Oak Ridge, Tennessee 37831-6283 \\ managed by \\ UT-BATTELLE, LLC \\ for the \\ US DEPARTMENT OF ENERGY \\ under contract DE-AC05-00OR22725
}

Approved For Public Release 


\section{CONTENTS}

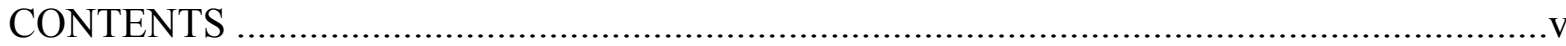

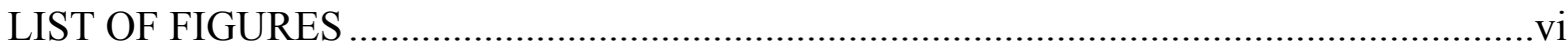

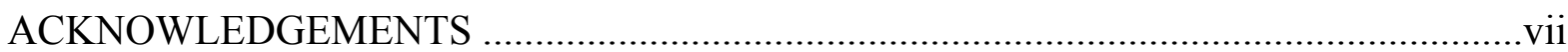

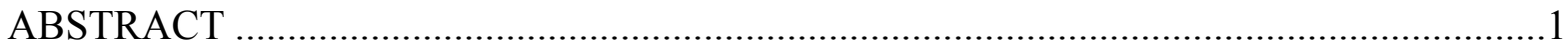

1. CONTROLLING MICROSTRUCTURE IN DEPOSITS FABRICATED USING

POWDER BLOWN DIRECT ENERGY DEPOSITION TECHNIQUE...............................1

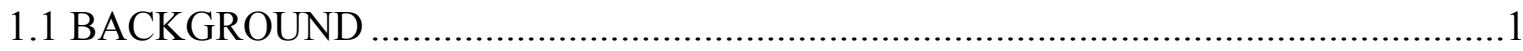

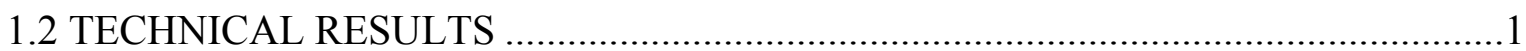

1.2.1 Fabrication of Builds Using Multiple Process Parameters ......................................

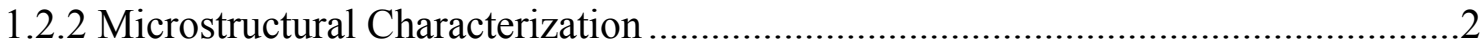

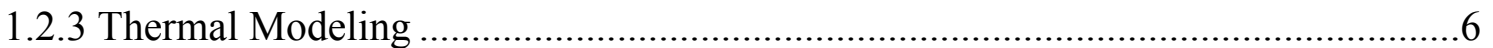

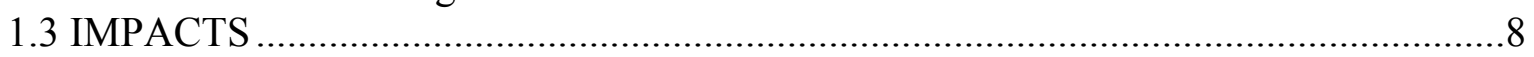

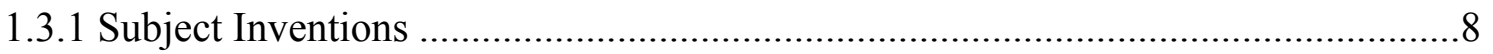

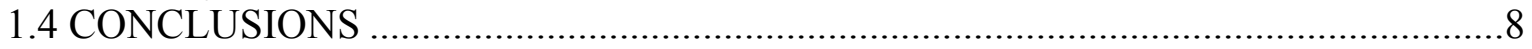

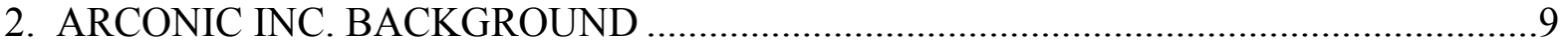

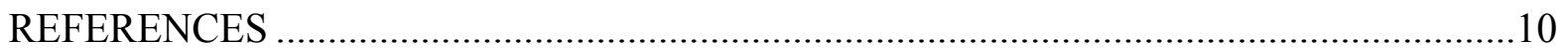




\section{LIST OF FIGURES}

Figure 1: Illustration of scan patterns used to fabricate builds. (a) Spot pattern (b) Raster pattern.

Figure 2: Inverse pole figures of samples fabricated using the line scan mode (a) Corresponds to the top zone of the build (b) corresponds to the middle zone and (c) corresponds to the bottom zone

Figure 3: Pole figures of samples fabricated using the line scan mode (a) Corresponds to the top zone of the build (b) corresponds to the middle zone and (c) corresponds to the bottom zone.

Figure 4: Inverse pole figures of samples fabricated using the spot mode (a) Corresponds to the top zone of the build (b) corresponds to the middle zone and (c) corresponds to the bottom zone.

Figure 5: Pole figures of samples fabricated using the spot scan mode (a) Corresponds to the top zone of the build (b) corresponds to the middle zone and (c) corresponds to the bottom zone.

Figure 6: Inverse pole figures of samples fabricated using the line scan mode with a pre heat (a) Corresponds to the top zone of the build (b) corresponds to the middle zone and (c) corresponds to the bottom zone.

Figure 7: Pole figures of samples fabricated using the line scan mode with a pre heat (a) Corresponds to the top zone of the build (b) corresponds to the middle zone and (c) corresponds to the bottom zone.

Figure 8: Thermal gradient for the processing parameters used in this study (a) $700 \mathrm{~W}$ and $700 \mathrm{~mm} / \mathrm{s}$ and a pre heat of $25^{\circ} \mathrm{C}$ (b) $700 \mathrm{~W}$ and $700 \mathrm{~mm} / \mathrm{s}$ and a pre heat of $450^{\circ} \mathrm{C}$ (c) $700 \mathrm{~W}$ and $700 \mathrm{~mm} / \mathrm{s}$ and a pre heat of $1200^{\circ} \mathrm{C}$.

Figure 9: Stray grain formation in the samples corresponding to the processing parameters used (a) $700 \mathrm{~W}$ and $700 \mathrm{~mm} / \mathrm{s}$ and a pre heat of $25^{\circ} \mathrm{C}$ (b) $700 \mathrm{~W}$ and $700 \mathrm{~mm} / \mathrm{s}$ and a pre heat of $450^{\circ} \mathrm{C}$ (c) $700 \mathrm{~W}$ and $700 \mathrm{~mm} / \mathrm{s}$ and a pre heat of $1200^{\circ} \mathrm{C}$. 


\section{ACKNOWLEDGEMENTS}

This CRADA NFE-16-06745 was conducted as a Technical Collaboration project within the Oak Ridge National Laboratory (ORNL) Manufacturing Demonstration Facility (MDF) sponsored by the US Department of Energy Advanced Manufacturing Office (CPS Agreement Number 24761).

Opportunities for MDF technical collaborations are listed in the announcement "Manufacturing Demonstration Facility Technology Collaborations for US Manufacturers in Advanced

Manufacturing and Materials Technologies" posted at http://web.ornl.gov/sci/manufacturing/docs/FBO-ORNL-MDF-2013-2.pdf. The goal of technical collaborations is to engage industry partners to participate in short-term, collaborative projects within the Manufacturing Demonstration Facility (MDF) to assess applicability and of new energy efficient manufacturing technologies. Research sponsored by the U.S. Department of Energy, Office of Energy Efficiency and Renewable Energy, Advanced Manufacturing Office, under contract DE-AC0500OR22725 with UT-Battelle, LLC. 


\begin{abstract}
The overall goal of this collaboration is to develop technologies to control grain morphology and microstructures of Inconel 718 components additively manufactured through the Direct Energy Deposition (DED) process (Identical to the LENS (laser engineered net shaping) processes) and to achieve equiaxed or near equiaxed grain structures. The phase 1 technical collaboration was used to fabricate Inconel 718 builds with different process parameters, pre heat and scan strategies. The results were then rationalized using computational heat transfer and solidification models.

Microstructural characterization showed that the aspect ratio of the grains can be reduced to less than 1.5 , and that control of the grain sizes to within $50-100 \mu \mathrm{m}$ could be potentially obtained by using an external source to preheat the substrate to $400^{\circ} \mathrm{C}$. Heat transfer models coupled with solidification models were used to rationalize the results which show that preheating lowered the temperature gradient thereby resulting in moving towards the equiaxed region of the columnar to equiaxed transition (CET) curve. The results demonstrate that higher preheat temperatures could be potentially used to obtain a truly equiaxed structure.
\end{abstract}

\title{
1. CONTROLLING MICROSTRUCTURE IN DEPOSITS FABRICATED USING POWDER BLOWN DIRECT ENERGY DEPOSITION TECHNIQUE
}

This phase 1 technical collaboration project (MDF-TC-17-116) was begun on July 17, 2017 and was completed on March 23, 2018. The collaboration partner Arconic Inc. is a large business. Results show that a comprehensive grain size control can be achieved in Inconel 718 using directed energy deposition processes.

\subsection{BACKGROUND}

Arconic currently supplies aero engine products through various traditional manufacturing processes and is looking for the Direct Energy Deposition DED Additive Manufacturing (AM) process to improve productivities, reduce costs and lead-times for the aforementioned products. Issues of the products manufactured through the LENS process include the long aspect ratios of grains, and the large variation of grain size distributions. These affect the uniformity of material properties and causes significant problems for ultrasonic nondestructive testing. ORNL has been working on microstructure control for AM process and has successfully developed techniques in this direction for electron-beam-powder bed-processes. By working with ORNL, Arconic may achieve commercial advantages in cost and lead-time as well as superior material properties through using the directed energy deposition (DED) processes. The preliminary experimental result and the modeling activities that were performed show that it is possible to control the grain size and texture in builds by controlling processing conditions. Among the processing parameters investigated here, the preheat temperature and scan strategy had the highest impact.

\subsection{TECHNICAL RESULTS}

\subsubsection{Fabrication of builds using multiple process parameters:}

A laser directed energy deposition technique was used to fabricate the builds. The builds were 
fabricated using a DM3D 103D directed energy deposition system. The system is equipped with a 1 $\mathrm{kW}$ diode laser with a wavelength of $910 \mathrm{~nm}$ and a spot size of $1.5 \mathrm{~mm}$. Three builds were fabricated using a laser power of $600 \mathrm{~W}$, a travel speed of $600 \mathrm{~mm} / \mathrm{min}$ and a powder flow rate of $5 \mathrm{gram} / \mathrm{minute}$ without an pre heat. Inconel 718 powder with a nominal composition shown in table-1 was used. The powder was gas atomized with a size distribution of 40-120 $\mu \mathrm{m}$.

Table:1 Composition of the Inconel 718 powder used to fabricate the builds

\begin{tabular}{|c|c|c|c|c|c|c|c|c|}
\hline Element & $\mathrm{Ni}$ & $\mathrm{Cr}$ & $\mathrm{Fe}$ & $\mathrm{Al}$ & $\mathrm{Ti}$ & $\mathrm{Nb}$ & $\mathrm{Mo}$ & $\mathrm{Co}$ \\
\hline Composition $\mathrm{wt} \%$ & 55 & 21 & Balance & 0.8 & 0.63 & 5.5 & 3.3 & 1.0 \\
\hline
\end{tabular}

A control sample was fabricated where the laser was used in the line/raster mode to build the part. $10 \times 10 \times 10 \mathrm{~mm}^{3}$ cubes were fabricated. To fabricate the second build the laser was used in the spot mode and pulsed. The laser on and off times were both $1 \mathrm{~ms}$ and the scan overlap was $0.6 \mathrm{~mm}$. The third sample was fabricated with the exact same processing conditions, however the preheat temperature was increased to $400^{\circ} \mathrm{C}$.

These processing conditions were selected based on previous work done in the literature which showed that the columnar to equiaxed transition can be affected by spatial and temporal variations in the thermal gradient $(\mathrm{G})$ and liquid solid interface velocities $(\mathrm{R})$. For instance Lim et.al have shown that this transition can be effected in Ni based alloys by magnetic arc oscillation [1]. They used thermal models to rationalize the observed results by showing that magnetic arc oscillation results in a shallow thermal gradient leading to the formation of an equiaxed microstructure [1]-[3]. These results were used to rationalize the results obtained by Dehoff et.al [4] and Raghavan et.al [5], [6] on the microstructures observed during the fabrication of Inconel 718 using electron beam additive manufacturing. Work in this research served as a basis for selecting the parameters used in this study.

Following deposition, the three builds were then sectioned for microstructure evaluation. Electron backscatter diffraction (EBSD) was used to characterize the grain structure and texture evolution in the samples at various locations of the build viz. top, middle and the bottom, and the results were contrasted and compared. The differences in the build scan strategies are summarized in figure 1 .
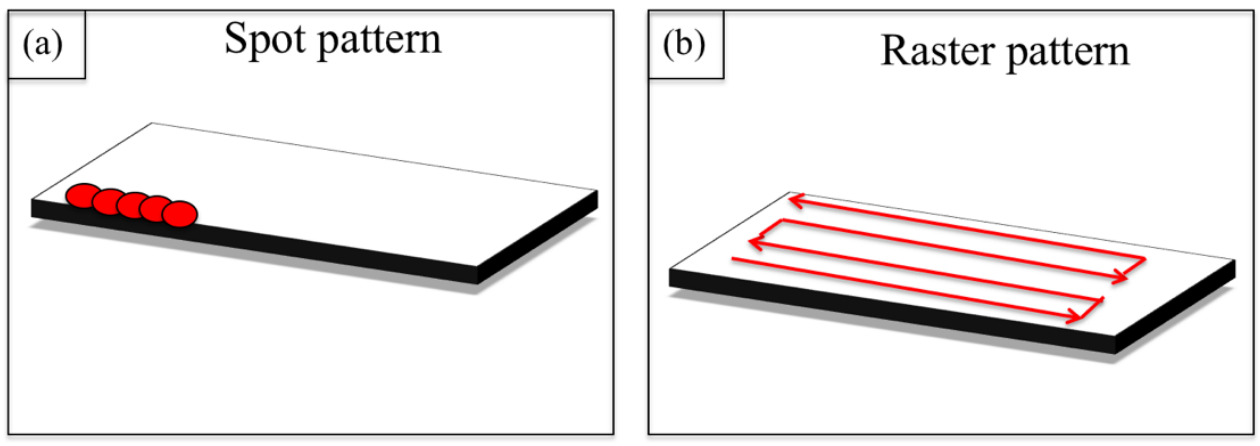

Figure 1: Illustration of scan patterns used to fabricate builds. (a) Spot pattern (b) Raster pattern.

\subsubsection{Microstructural Characterization}




\subsubsection{Control sample: Sample scanned with raster path}

The results from EBSD are presented in figure 2. The EBSD clearly shows that the grain structure is predominantly columnar with an average grain size of $\sim 300 \mu \mathrm{m}$.

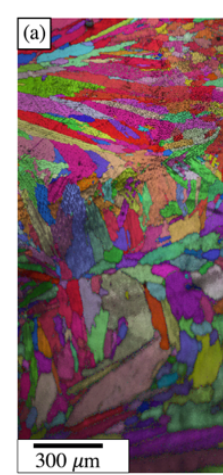

Top zone

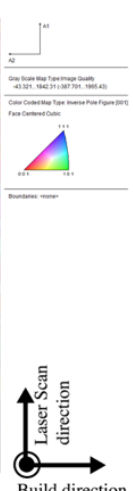

Build directio

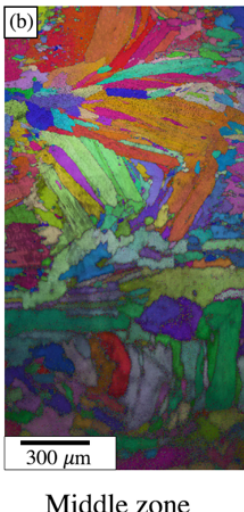

Middle zone

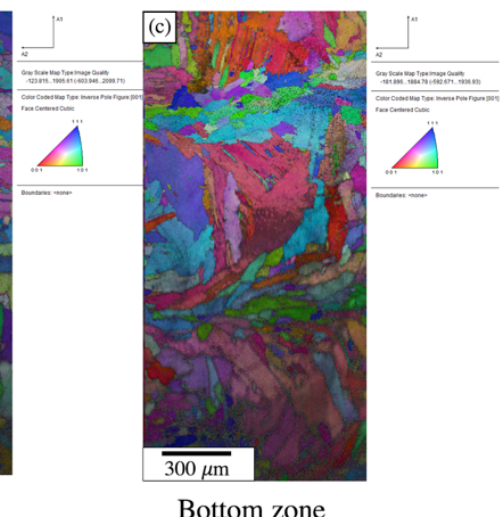

Bottom zone

Figure 2: Inverse pole figures of samples fabricated using the line scan mode (a) Corresponds to the top zone of the build (b) corresponds to the middle zone and (c) corresponds to the bottom zone

The micro texture evolution at all the three locations for the line scan sample are shown in figure 3 . Figure 3(a) shows the micro texture pole figure map in the different zones of the sample corresponding to the EBSD micrograph shown in the previous figure. The plot shows the concentration of the various poles $(<100>,<110>$ and $<111>)$ with respect to the build direction (marked A1) and the laser beam direction (marked A2). The sample clearly shows that most of the grains are $<100>||$ Build direction (where the $<100>$ direction of the grains are aligned with the build direction). Figure 3(b) and (c) correspond to the middle and bottom zone respectively also show similar texture evolved. The texture is slightly stronger at the bottom and the middle with a strength of 5 times random and at the top zone the strength weakens further with an intensity of only 3 times random. This could be attributed to increase in the sample temperature along the $\mathrm{Z}$ direction leading to the breakdown of the texture due to constitutional super cooling [7].

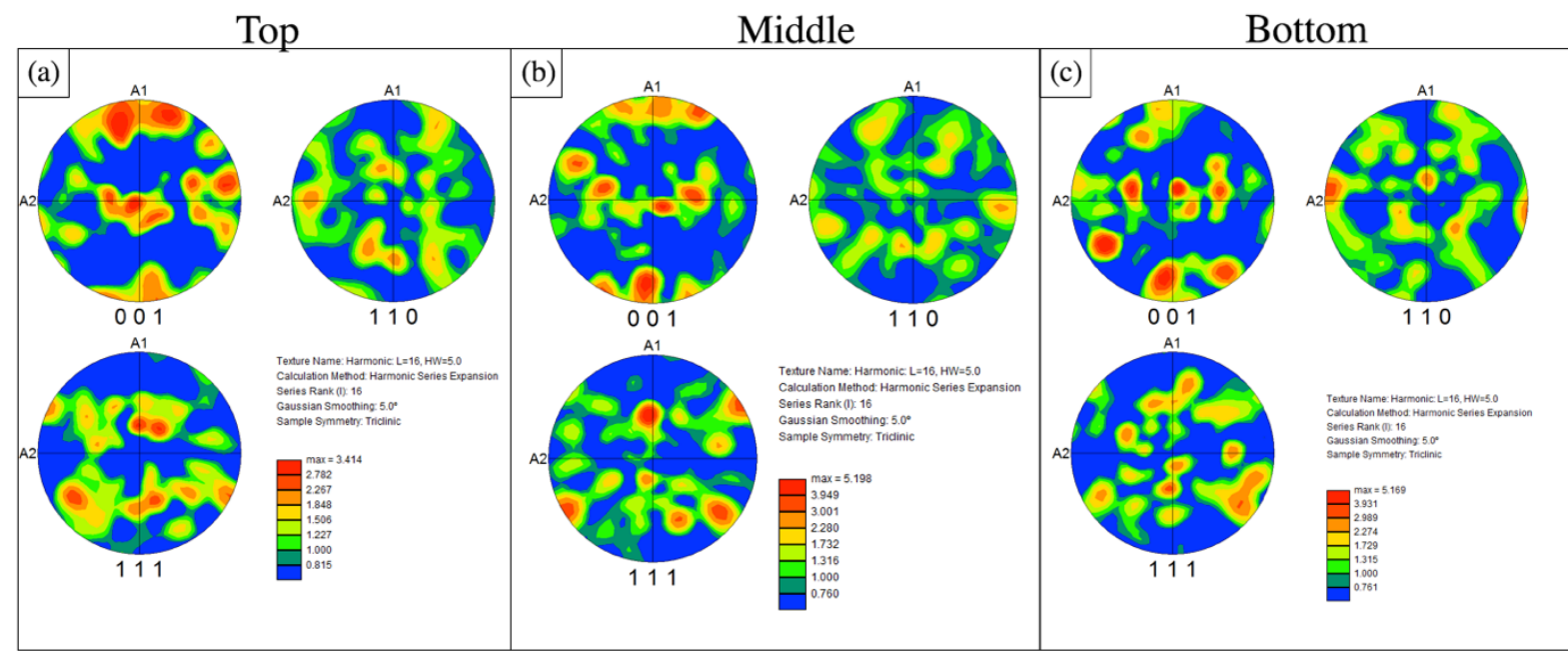

Figure 3: Pole figures of samples fabricated using the line scan mode (a) Corresponds to the top zone of the build (b) corresponds to the middle zone and (c) corresponds to the bottom zone. 


\subsubsection{Pulsed laser sample:}

The results from the EBSD are presented in figure 4. Figure 4(a), (b) and (c) corresponds to the micrograph obtained from the bottom, middle and top of the builds respectively. The EBSD micrographs clearly show that the grain size is close to $\sim 450 \mu \mathrm{m}$. Also note that the grains are more columnar compared to the grain structure obtained after fabricating the deposits using the line scan strategy. The reason for this highly columnar growth is attributed to the fact that the thermal gradients are much steeper while building in the spot mode as opposed to a line mode. This steep thermal gradient leads to a uniform columnar growth in the entire build.

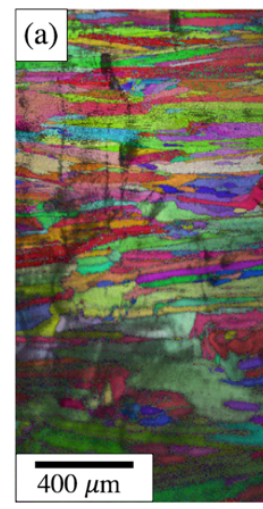

Top zone

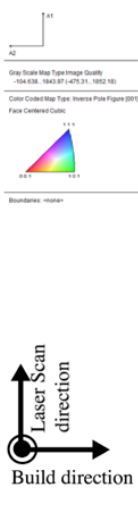

Middle zone

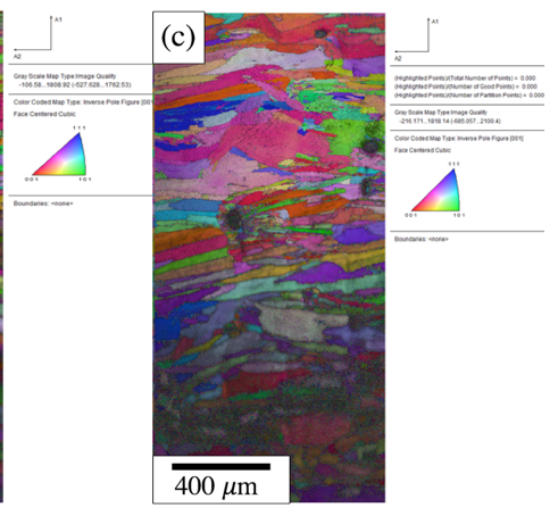

Bottom zone

Figure 4: Inverse pole figures of samples fabricated using the spot mode (a) Corresponds to the top zone of the build (b) corresponds to the middle zone and (c) corresponds to the bottom zone.

The micro texture results for the pulsed laser sample are presented in figure 5 (a), (b) and (c) corresponding to the bottom, middle and top zones respectively. Note that the texture obtained by fabricating the deposits in the line mode clearly shows that the $\langle 100>\|$ build direction. The texture is stronger, with a strength of 7 times random as opposed to the 5 times random as observed previously.

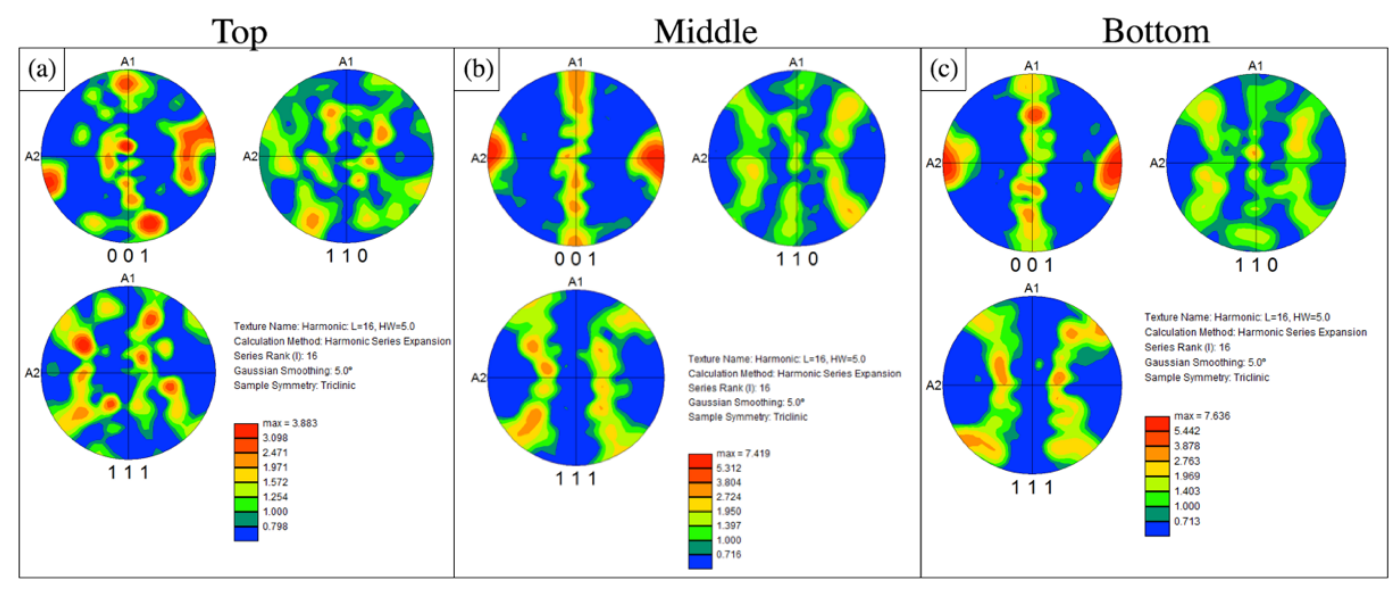

Figure 5: Pole figures of samples fabricated using the spot scan mode (a) Corresponds to the top zone of the build (b) corresponds to the middle zone and (c) corresponds to the bottom zone. 


\subsubsection{Samples fabricated using $400^{\circ} \mathrm{C}$ pre heat:}

The EBSD results for the samples fabricated by pre heating the substrate to $400^{\circ} \mathrm{C}$ are presented in figure 6. Figure 6(a), (b) and (c) corresponds to the micrograph obtained from the bottom, middle and top zones of the builds respectively. The EBSD micrographs clearly show that the grains are nonuniform, and there is a breakdown in the columnar morphology of the grains. The grain size is significantly finer in specific places, primarily promoted by constitutional super cooling ahead of the liquid solid interface due to the shallower thermal gradient.

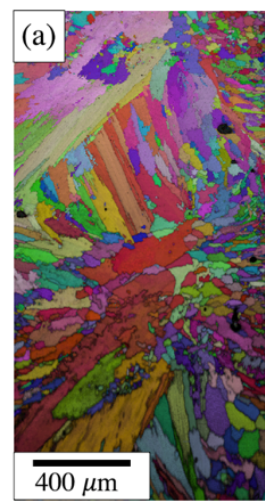

Top zone

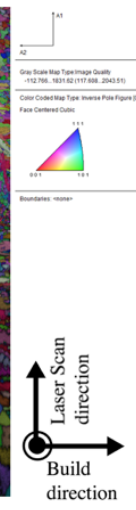

direction

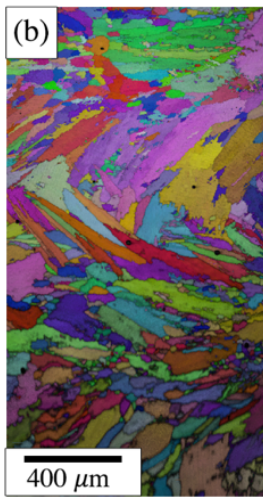

Middle zone

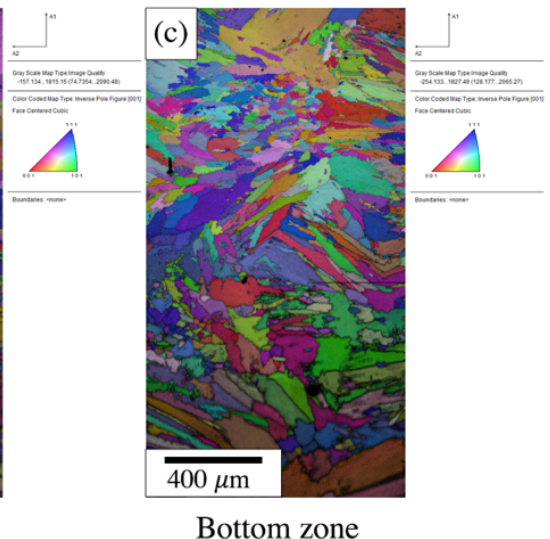

Bottom zone

Figure 6: Inverse pole figures of samples fabricated using the line scan mode with a pre heat (a) Corresponds to the top zone of the build (b) corresponds to the middle zone and (c) corresponds to the bottom zone.

The micro texture of different zones in the builds are presented in figure 7 (a), (b), and (c). The microtexture results clearly shows weakening compared to the previous two deposits with a strength of 3 times random as shown in the figure. To rationalize the weakening of the texture computational heat transfer models were employed to study the impact of the processing conditions on the melt pool and the results are presented in the following sections.

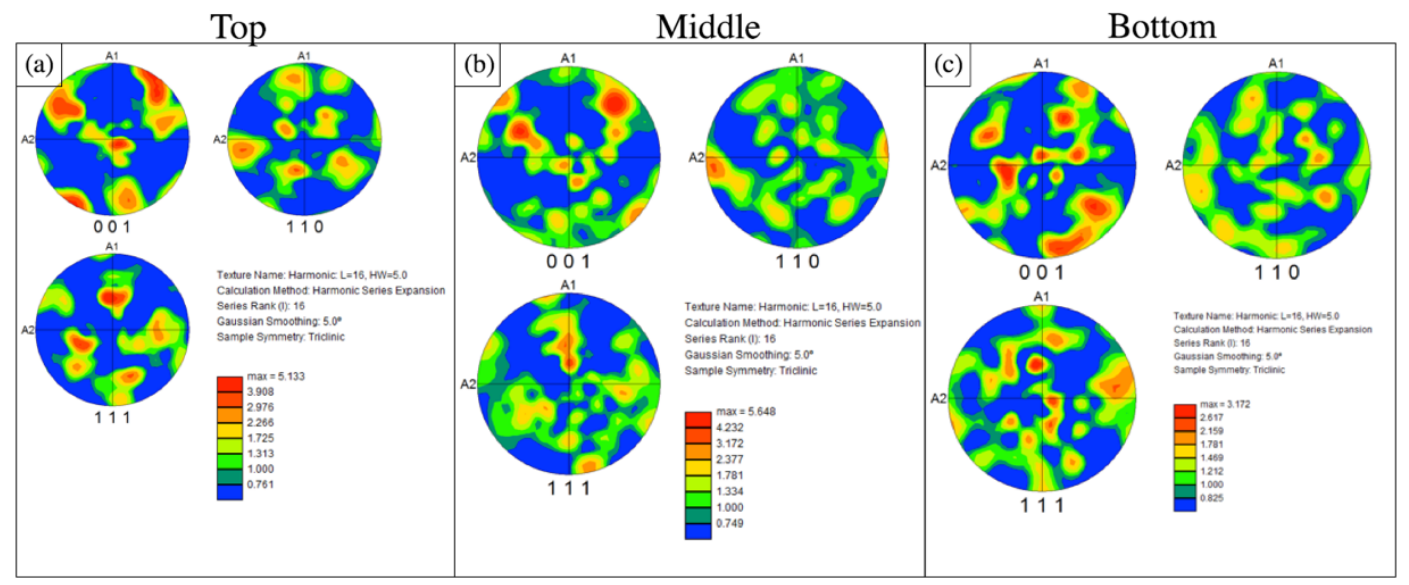

Figure 7: Pole figures of samples fabricated using the line scan mode with a pre heat (a) Corresponds to the top zone of the build (b) corresponds to the middle zone and (c) corresponds to the bottom zone. 


\subsubsection{Thermal Modeling:}

During rapid solidification conditions occurring in this process, the solidification grain morphology is dictated by the local solidification parameters. The primary solidification parameters are (a) thermal gradient at the liquid-solid interface $-\mathrm{G}$ and (b) velocity of the liquid-solid interface - $\mathrm{R}$. Understanding the spatio-temporal variation of these parameters is pivotal in the solidification microstructure control. Truchas [8], an open-source numerical code developed at Los Alamos National Laboratory is used to simulate the process and extract the $\mathrm{G}$ and $\mathrm{R}$ values as a function of processing parameters. Conservation equation solved by the framework is given in equation 1 .

$$
\frac{\partial(\rho h)}{\partial t}=\nabla \cdot(k \nabla T)+S
$$

Where $\rho$ is the density, $\mathrm{k}$ is the thermal conductivity, $\mathrm{h}$ is the specific enthalpy and $\mathrm{S}$ is the source term. The source term includes both positive and negative fluxes. Some of the source terms considered for the additive manufacturing problem are

- Heat source used to melt the powder particles (laser).

- Latent heat evolution during phase change.

- Radiative and convective heat fluxes at the boundaries.

The surface heat source profile is defined by the Gaussian profile given in equation (2).

$$
\mathrm{I}=\left(\frac{1}{2 \pi \sigma^{2}}\right) e^{-\frac{1}{2 \sigma^{2}}\left(x^{2}+y^{2}\right)}
$$

where $\mathbf{I}$ is the surface intensity profile, $\sigma$ is the standard deviation related to the beam diameter, $\mathrm{x}$ and $\mathrm{y}$ are the distance from the center of the beam in $\mathrm{X}$ and $\mathrm{Y}$ axis respectively. The calculated temperature profile is post-processed to predict the $\mathrm{G}$ and $\mathrm{R}$ at the liquid-solid interface. The transient temperature gradient $(\mathbf{G})$ at the liquid-solid interface of the domain is calculated according to equation (3) using the spatial and temporal distribution of temperature within the melt pool.

Thermal Gradient $G(K / m)=\sqrt{G_{x}^{2}+G_{y}^{2}+G_{z}^{2}}$

where $\mathbf{G}_{\mathbf{x}}, \mathbf{G}_{\mathbf{y}}$ and $\mathbf{G}_{\mathbf{z}}$ are temperature gradients at the liquid-solid interface along $\mathrm{X}, \mathrm{Y}$ and $\mathrm{Z}$ directions respectively. Liquid-solid interface velocity is calculated using cooling rate and temperature gradient as formulated in equations $(4,5,6)[8]$.

$$
\begin{aligned}
& \text { liquid Solid interface velocity } R(\mathrm{~m} / \mathrm{s})=\frac{\mid \text { Cooling Rate } \mid(\mathrm{K} / \mathrm{s})}{\mid \text { Thermal Gradient } \mid(\mathrm{K} / \mathrm{m})} \\
& \text { Cooling Rate }\left(\frac{\mathrm{K}}{\mathrm{s}}\right)=\left|\frac{\mathrm{dT}}{\mathrm{dt}}\right|
\end{aligned}
$$

Liquid Solid interface velocity $R(\mathrm{~m} / \mathrm{s})=\frac{\left|\frac{\mathrm{dT}}{\mathrm{dt}}\right|}{\sqrt{\mathrm{G}_{\mathrm{x}}^{2}+\mathrm{G}_{\mathrm{y}}^{2}+\mathrm{G}_{\mathrm{z}}^{2}}}$ 
The spatiotemporal $\mathrm{G}$ and $\mathrm{R}$ data is then used to calculate the volume fraction of stray grains formed during the solidification using following equation [5].

$\Phi=1-\exp \left\{-2.358 \mathrm{E} 19 *\left(\frac{\mathrm{R}}{\mathrm{G}^{3.4}}\right)^{\frac{3}{3.4}}\right\}$

Thermal simulations were performed for the currently used process parameters of $700 \mathrm{~W}$ and $700 \mathrm{~mm} / \mathrm{s}$ at two different preheat temperature of $25^{\circ} \mathrm{C}$ and $450^{\circ} \mathrm{C}$. In addition, a hypothetical preheat condition was used in the simulations to understand the necessary preheat required to transition to a completely equiaxed structure. This preheat was close to $1200^{\circ} \mathrm{C}$. Consequently, the thermal gradient and the liquid solid interface velocities were calculated for these conditions. The gradients are showed in figure 8 . Figure 8(a) shows the thermal gradients for a pre heat of $25^{\circ} \mathrm{C}$, while figure $8(\mathrm{~b})$ shows the thermal gradient for a pre heat of $450^{\circ} \mathrm{C}$ and figure $8(\mathrm{c})$ shows the thermal gradient for a pre heat of $1200^{\circ} \mathrm{C}$.

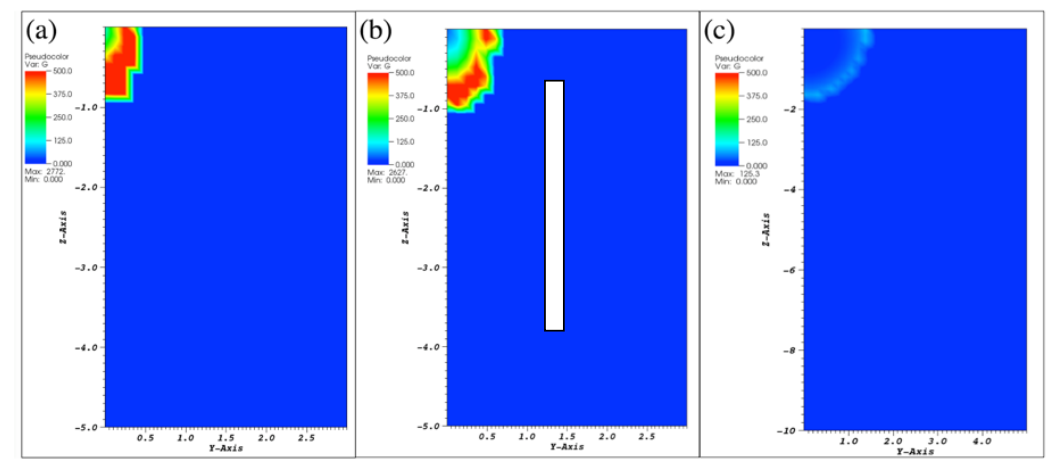

Figure 8: Thermal gradient for the processing parameters used in this study (a) $700 \mathrm{~W}$ and $700 \mathrm{~mm} / \mathrm{s}$ and a pre heat of $25^{\circ} \mathrm{C}$ (b) $700 \mathrm{~W}$ and $700 \mathrm{~mm} / \mathrm{s}$ and a pre heat of $4500^{\circ} \mathrm{C}$ (c) $700 \mathrm{~W}$ and $700 \mathrm{~mm} / \mathrm{s}$ and a pre heat of $1200^{\circ} \mathrm{C}$.

The results clearly show that increasing the preheat temperature results in a shallow thermal gradient. The influence of these process parameters on the columnar to equiaxed structure is shown in figure 9. Figure 9 shows the influence of process parameters on the stray grain formation. The results show that the increasing the preheat results in a higher fraction of stray grains.

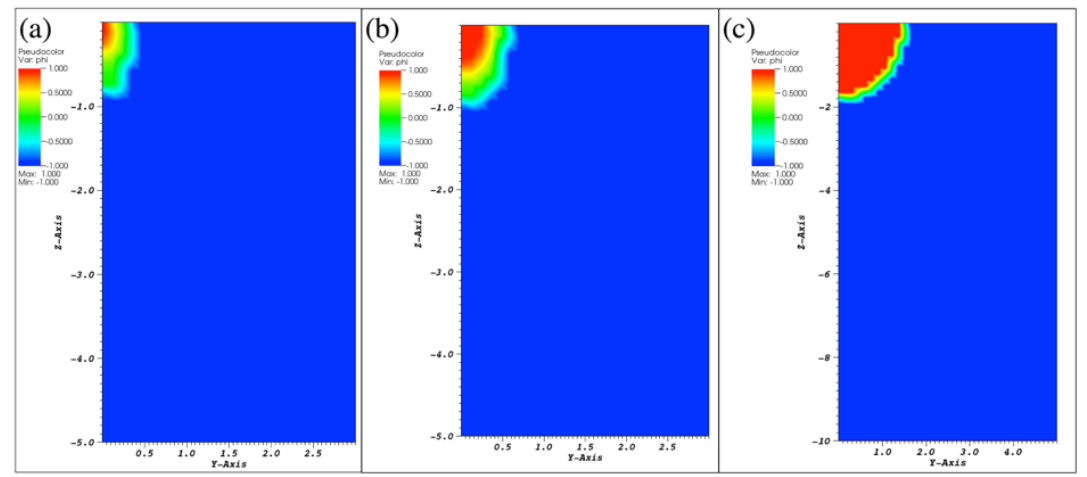

Figure 9: Stray grain formation in the samples corresponding to the processing parameters used (a) $700 \mathrm{~W}$ and $700 \mathrm{~mm} / \mathrm{s}$ and a pre heat of $25^{\circ} \mathrm{C}$ (b) $700 \mathrm{~W}$ and $700 \mathrm{~mm} / \mathrm{s}$ and a pre heat of $450^{\circ} \mathrm{C}$ (c) $700 \mathrm{~W}$ and $700 \mathrm{~mm} / \mathrm{s}$ and a pre heat of $1200^{\circ} \mathrm{C}$. 


\subsection{IMPACTS}

This work has demonstrated the potential of using the laser powder blown DMD system to control the microstructure and avoid the columnar grain structure in Inconel 718 builds. Using the information generated in this Phase 1 technical collaborations program it will be possible for the partner to move towards getting a completely equiaxed or a highly mis-orientated growth structure in future builds. This breakthrough is crucial to the partner from a perspective of an enhanced Non-Destructive Evaluation (NDE), response and could also lead to a paradigm of tailoring the microstructure to get site specific mechanical properties.

\subsubsection{Subject Inventions}

There are no subject inventions associated with this CRADA.

\subsection{CONCLUSIONS}

As stated in the previous sections, the goal of the phase 1 of this technical collaboration program was to understand the feasibility of transitioning from a columnar to equiaxed structure in directed energy deposition processes. To this effect multiple builds were fabricated where the scan pattern and pre heat temperature of the builds were varied. The results clearly demonstrate the feasibility of transitioning from a highly textured columnar growth mode to a misoriented growth mode at higher pre heat temperatures. Thermal modeling was used to rationalize these results in the context of wellknown solidification theories. The modeling confirms previously shown results that a shallower thermal gradient leads to significant constitutional super cooling ahead of the liquid solid solidification front leading to a more equiaxed structure.

\section{ARCONIC INC. BACKGROUND}

Arconic Inc. (formerly Alcoa Inc.) is engaged in providing materials and engineered products. Arconic operates through segments, including Global Rolled Products, Engineered Products and Solutions, and Transportation and Construction Solutions. The Company offers engineered products and solutions, including fastening systems and rings, titanium and engineered products, power and 
propulsion, and forgings and extrusions. Its transportation and construction solutions include wheel and transportation products; building and construction systems, and extrusions. Its global rolled products include aerospace and automotive products; Micro mill products and services, and brazing, commercial transportation and industrial solutions. It offers a range of aluminum sheet and plate products for the aerospace, automotive, commercial transportation, brazing and industrial markets. 


\section{REFERENCES}

[1] Y. C. Lim et al., "Effect of magnetic stirring on grain structure refinement Part 2 - Nickel alloy weld overlays," Sci. Technol. Weld. Join., vol. 15, no. 5, pp. 400-406, 2010.

[2] Y. C. Lim et al., "Effect of magnetic stirring on grain structure refinement: Part 1 Autogenous nickel alloy welds," Sci. Technol. Weld. Join., vol. 15, no. 7, pp. 583-589, 2010.

[3] X. Yu et al., "Reducing hot cracking tendency of dissimilar weld overlay by magnetic arc oscillation," Mater. Sci. Technol., vol. 30, no. 8, pp. 930-937, 2014.

[4] R. R. Dehoff et al., "Site specific control of crystallographic grain orientation through electron beam additive manufacturing," Mater. Sci. Technol., vol. 31, no. 8, pp. 931-938, 2015.

[5] N. Raghavan et al., "Localized melt-scan strategy for site specific control of grain size and primary dendrite arm spacing in electron beam additive manufacturing," Acta Mater., vol. 140, pp. 375-387, 2017.

[6] N. Raghavan et al., "Corrigendum to 'Numerical modeling of heat-transfer and the influence of process parameters on tailoring the grain morphology of IN718 in electron beam additive manufacturing' [Acta Mater. 112C (2016) 303-314], (S1359645416302294), (10.1016/j.actamat.2016.03.063))," Acta Materialia, vol. 140. p. 472, 2017.

[7] W. Kurz, C. Bezençon, and M. Gäumann, "Columnar to equiaxed transition in solidification processing,” Sci. Technol. Adv. Mater., vol. 2, no. 1, pp. 185-191, 2001.

[8] D. A. Korzekwa, "Truchas - a multi-physics tool for casting simulation," Int. J. Cast Met. Res., vol. 22, no. 1-4, pp. 187-191, 2009. 